\title{
Mechanism of Enhanced Na-K-ATPase Activity in Cortical Collecting Duct from Rats with Nephrotic Syndrome
}

\author{
Eric Féraille, * Bruno Vogt, * Martine Rousselot, ${ }^{*}$ Catherine Barlet-Bas, ${ }^{\star}$ Lydie Cheval, ${ }^{\star}$ Alain Doucet, ${ }^{\star}$ and Hervé Favre ${ }^{\star}$ \\ ${ }^{*}$ Division de Néphrologie, Hôpital Cantonal Universitaire de Genève, 1211 Genève 4, Switzerland; and ${ }^{\ddagger}$ Laboratoire de Physiologie \\ Cellulaire, Centre National de la Recherche Scientifique URA 219, Collège de France, 75231 Paris, Cedex 05, France
}

\begin{abstract}
The maximal hydrolytic activity of Na-K-ATPase is specifically increased in the cortical collecting duct (CCD) of rats with puromycin-induced nephrotic syndrome (NS). This stimulation is independent of aldosterone and of endogenous ouabain-like substance. To investigate the mechanism responsible for this change, we compared the maximal Na-K-ATPase hydrolytic activity, the ouabain sensitive ${ }^{86} \mathrm{Rb}$ influx, the specific $\left[{ }^{3} \mathrm{H}\right]$ ouabain binding, and the sensitivity of Na-K-ATPase to ouabain in the $\mathrm{CCD}$ of control rats and of rats given an intraperitoneal injection of puromycin $7 \mathrm{~d}$ before study. Both Na-K-ATPase activity and ouabain-sensitive ${ }^{86} \mathbf{R b}$ influx increased twofold in rats with NS (ATPase activity: $34.1 \pm 2.1$ vs. $18.0 \pm 0.7$ $\mathrm{pmol} \cdot \mathrm{mm}^{-1} \cdot \min ^{-1} \pm \mathrm{SE}, n=6, P<0.001 ; \mathrm{Rb}$ influx: $14.4 \pm 0.7$ vs. $\left.7.4 \pm 0.4 \mathrm{peq} \cdot \mathrm{min}^{-1} \pm \mathrm{SE}, n=6, P<0.001\right)$ whereas specific $\left[{ }^{3} \mathrm{H}\right]$ ouabain binding decreased in rats with NS (6.9 $\pm 0.7 \mathrm{vs.}$ $\left.9.0 \pm 0.6 \mathrm{fmol} \cdot \mathrm{mm}^{-1} \pm \mathrm{SE}, n=6, P<0.005\right)$. Therefore, the maximal turnover rate of $\mathrm{Na}-\mathrm{K}$-ATPase increased over twofold in rats with $\mathrm{NS}\left(5,053 \pm 361 \mathrm{vs} .2,043 \pm 124 \mathrm{cycles} \cdot \mathrm{min}^{-1} \pm \mathrm{SE}\right.$, $n=6, P<0.001$ ). Analysis of the curves of inhibition of $\mathrm{Na}-\mathrm{K}$ ATPase by ouabain showed the presence of two Na-K-ATPase populations in both control and NS rats: a highly sensitive population (apparent $\mathrm{Ki}: 1.4 \times 10^{-6} \mathrm{M}$ and $0.9 \times 10^{-6} \mathrm{M}$ ) and a less sensitive moiety (apparent $\mathrm{Ki}: 2.6 \times 10^{-4} \mathrm{M}$ and $1.1 \times 10^{-4}$ $M)$. The enhancement of Na-K-ATPase activity observed in the CCD of rats with NS was entirely due to the stimulation of the population of $\mathrm{Na}-\mathrm{K}-\mathrm{ATPase}$ with low ouabain sensitivity. These results suggest that a dysregulation of this subclass of Na-K-ATPase might be the primary cause of sodium retention in this model of nephrotic syndrome. (J. Clin. Invest. 1993. 91:1295-1300.) Key words: adenosine triphosphatase • sodium - ouabain • rubidium uptake • collecting tubule
\end{abstract}

\section{Introduction}

We have previously reported that Na-K-ATPase hydrolytic activity measured under optimal conditions is enhanced specifically in the cortical collecting duct $(\mathrm{CCD})^{1}$ of rats with puro-

Address reprint requests to E. Féraille, Division de Néphrologie, Hôpital Cantonal Universitaire de Genève, 24, rue Micheli-du-Crest, 1211 Genève 14 , Switzerland.

Received for publication 5 June 1992 and in revised form 29 September 1992.

1. Abbreviations used in this paper: CCD, cortical collecting duct; NS, puromycin induced nephrotic syndrome

J. Clin. Invest.

(C) The American Society for Clinical Investigation, Inc.

0021-9738/93/04/1295/06 \$2.00

Volume 91, April 1993, 1295-1300 mycin-amino-nucleoside induced nephrotic syndrome (NS) (1). In this experimental model, micropuncture studies have revealed that the CCD is also the only site of the nephron where sodium reabsorption is increased (2). The increase in Na-KATPase activity in the CCD of nephrotic rats was not altered by adrenalectomy (1), suggesting that aldosterone was not involved in this adaptation. Neither was it related to the endogenous ouabain-like factor (3), which preferentially inhibits renal Na-K-ATPase in the CCD (4), since the renal concentration of this factor was increased in NS rats.

The control of Na-K-ATPase activity is multifactorial; in addition to hormonal regulation, other factors are involved. Intracellular sodium concentration (5-7), sodium affinity of Na-K-ATPase $(5,8), \mathrm{K}$ conductance $(9)$ and transmembrane voltage (10) are limiting factors evidenced only in intact cells and not taken into account when the hydrolytic activity of the enzyme is measured under optimal conditions, on permeabilized cells. The increased specific activity of the Na-K-ATPase in CCD of NS rats found in these latter conditions could be the direct consequence of a change in the number of Na-K-ATPase units and/or in enzymatic turnover.

To study the mechanism(s) responsible for the enhancement of Na-K-ATPase activity observed in nephrotic rats, we determined in isolated CCD from control and nephrotic rats: (a) the ouabain sensitive ${ }^{86} \mathrm{Rb}$ influx, $(b)$ the rate of Na-K-ATPase hydrolytic activity under optimal conditions, $(c)$ the specific $\left[{ }^{3} \mathrm{H}\right]$ ouabain binding, and $(d)$ the ouabain sensitivity of Na-K-ATPase.

\section{Methods}

Experimental model. Experiments were carried out on male Wistar rats (Physiopathology Institute, Bern, Switzerland) weighing 100-140 $\mathrm{g}$ when they entered the study. Nephrotic syndrome was induced by a single injection ( $15 \mathrm{mg}$ per $100 \mathrm{~g}$ body wt i.p. within $1 \mathrm{ml}$ of $0.9 \%$ $\mathrm{NaCl}$ ) of puromycin aminonucleoside (SERVA Feinbiochemica, Heidelberg, FRG) (11). Control rats received a single intraperitoneal injection of the vehicle. All experiments were performed $7 \mathrm{~d}$ after puromycin aminonucleoside or sham injection.

Isolation of single CCD. After anesthesia (pentobarbital $5 \mathrm{mg}$ per $100 \mathrm{~g}$ body wt., i.p.), the left kidney was quickly perfused through a catheter inserted into the abdominal aorta with $4 \mathrm{ml}$ of dissection solution (see composition below) containing $0.18 \%$ (wt/vol) collagenase (from Clostridium histolyticum, $0.87 \mathrm{U} / \mathrm{mg}$, SERVA Feinbiochemica). After perfusion, the kidney was immediately removed and sliced into small pyramids, which were incubated at $30^{\circ} \mathrm{C}$ for $20 \mathrm{~min}$ in aerated dissection solution containing $0.09 \%(w t / v o l)$ collagenase. Pyramids were then thoroughly rinsed in ice-cold dissection solution and stored in the cold until use. CCD were microdissected in dissection solution at $0-4^{\circ} \mathrm{C}$ under stereomicroscopic observation. They were identified by morphological and topographical criteria as previously described (12).

For ATPase activity and $\left[{ }^{3} \mathrm{H}\right]$ ouabain binding experiments, the dissection solution contained $(\mathrm{mM}): 137 \mathrm{NaCl}, 5 \mathrm{KCl}, 0.8 \mathrm{MgSO}_{4}$, $0.33 \mathrm{NaH}_{2} \mathrm{PO}_{4}, 0.44 \mathrm{KH}_{2} \mathrm{PO}_{4}, 1 \mathrm{MgCl}_{2}, 10$ Tris $\mathrm{HCl}$ and $1 \mathrm{CaCl}_{2}, \mathrm{pH}$ 
7.4. For ${ }^{86} \mathrm{Rb}$ uptake experiments, the dissection solution contained $(\mathrm{mM}): 120 \mathrm{NaCl}, 5 \mathrm{RbCl}, 1 \mathrm{CaCl}_{2}, 1 \mathrm{MgSO}_{4}, 0.2 \mathrm{Na}_{2} \mathrm{HPO}_{4}, 0.15$ $\mathrm{Na}_{2} \mathrm{HPO}_{4}, 5$ glucose, 2 lactate, 4 essential and nonessential amino acids, 0.03 vitamins, and 20 Hepes; BSA $0.1 \%$ (wt/ vol) was added and the $\mathrm{pH}$ was adjusted to 7.45 . The osmolarity was adjusted to 400 mos$\mathrm{mol} / \mathrm{kg}$ by mannitol addition.

Na-K-ATPase hydrolytic activity. Na-K-ATPase activity was determined by a radiochemical assay based on the measurement of Pi released from $\left[\gamma^{32} \mathrm{P}\right] \mathrm{ATP}$ by the ATPase contained in a single CCD as previously described (13). Briefly, each tubule was individually transferred with $1 \mathrm{ml}$ of dissection solution into the concavity of a sunken bacteriological slide coated with dried BSA. The length of each tubule, which served as reference for ATPase activity, was determined by photography. Unless otherwise indicated, the tubules were then thoroughly rinsed with ice-cold distilled water and submitted to a freezing/thawing step in $0.2 \mathrm{ml}$ of distilled water. This procedure permitted the removal of ions and the permeabilization of cell membranes, allowing the access of substrates into the cells.

After addition of $1 \mathrm{ml}$ of ATPase assay solution (see composition below), samples were incubated for $15 \mathrm{~min}$ at $37^{\circ} \mathrm{C}$. Incubation was stopped by cooling and by addition of $5 \mathrm{ml} \mathrm{of} 5 \%$ ( wt/ vol ) cold trichloracetic acid. Samples were then transferred into $2 \mathrm{ml}$ of a suspension of $10 \%(\mathrm{wt} / \mathrm{vol}$ ) activated charcoal. After mixing and centrifugation, the radioactivity was measured by liquid scintillation on 500 -ml aliquots of supernatant, which contain the Pi formed from ATP. ATPase assay solution contained $(\mathrm{mM}): 50 \mathrm{NaCl}, 5 \mathrm{KCl}, 10 \mathrm{MgCl}_{2}, 1$ EDTA, 100 Tris $\mathrm{HCl}, 10 \mathrm{Na}_{2} \mathrm{ATP}$, and tracer amounts $(5 \mathrm{nCi} / \mathrm{ml})$ of $\left[\gamma^{-32} \mathrm{P}\right]$ ATP (Dupont de Nemours, 2-10 Ci/mmol) for total ATPase activity. For basal $\mathrm{Mg}$-ATPase activity, $\mathrm{NaCl}$ and $\mathrm{KCl}$ were omitted, Tris $\mathrm{HCl}$ was $150 \mathrm{mM}$, and $1 \mathrm{mM}$ ouabain was added. The $\mathrm{pH}$ of both solutions was adjusted to 7.4. In preliminary experiments we verified that these assay conditions were optimal in NS rats as previously reported in normal animals (13).

In each experiment, total and $\mathrm{Mg}$-ATPase activities were each determined on 5-7 replicates either for NS or control rats. Na-K-ATPase activity was taken as the difference between the mean total ATPase and the mean Mg-ATPase activity. Na-K-ATPase activity was expressed as pmol ATP $\cdot \min ^{-1} \cdot \mathrm{mm}^{-1}$ and the data are means \pm SE from several animals.

${ }^{86} \mathrm{Rb}$ uptake. ${ }^{86} \mathrm{Rb}$ uptake was determined in intact tubules by measuring the intracellular accumulation of ${ }^{86} \mathrm{Rb}$ under initial rate conditions, according to the method previously described (14), with slight modifications. After dissection, 7-8 CCD were transferred in $1 \mathrm{ml}$ of dissection solution into the concavity of a sunken bacteriological slide coated with dried BSA. Then the tubules were preincubated at $37^{\circ} \mathrm{C}$ for $10 \mathrm{~min}$ to allow the restoration of transmembrane ion gradients as well as the binding of ouabain when present. ${ }^{86} \mathrm{Rb}$ uptake was determined after addition of $0.5 \mathrm{ml}$ of dissection solution containing ${ }^{86} \mathrm{RbCl}$ (Amersham, Buckinghamshire, UK) in tracer amounts (about 100 $\mathrm{nCi} /$ sample) and preequilibrated at $37^{\circ} \mathrm{C}$. Incubation was stopped after $1 \mathrm{~min}$ by adding $50 \mathrm{ml}$ of ice-cold rinsing solution that contains (mM): 140 choline chloride, $1.2 \mathrm{MgCl}_{2}, 3 \mathrm{BaCl}_{2}, 10 \mathrm{Hepes}, 0.1 \%$ (wt/ vol) BSA, and mannitol up to $400 \mathrm{mosmol} \cdot \mathrm{kg}^{-1}, \mathrm{pH} 7.45$. The tubules of each slide were then rapidly rinsed in three successive baths of ice-cold rinsing solution and individually transferred with $0.2 \mathrm{ml}$ of the last rinsing solution on a small microscopic cover slide. After determination of its length, each sample was dropped into a counting vial containing $0.5 \mathrm{ml}$ of $1 \%(\mathrm{wt} / \mathrm{vol})$ deoxycholic acid, and its radioactivity was measured by liquid scintillation counting. In each experiment, the blank value, which was subtracted from all values, was determined as the mean radioactivity of 5-10 replicate samples consisting of $0.2 \mathrm{ml}$ of the last rinsing solution.

Ouabain-sensitive $\mathrm{Rb}$ uptake was calculated as the difference between the mean values measured in samples incubated without ouabain and with $2 \mathrm{mM}$ ouabain, respectively. Rb uptake was expressed as peq $\mathrm{Rb} \cdot \mathrm{min}^{-1} \cdot \mathrm{mm}^{-1}$, and data are means $\pm \mathrm{SE}$ from several animals.

$\left[{ }^{3} \mathrm{H}\right]$ Ouabain binding. $\left[{ }^{3} \mathrm{H}\right]$ Ouabain binding was measured in intact tubules as previously described $(15,16)$. Briefly, after dissection and photography each tubule was transferred in $1 \mathrm{ml}$ of dissection solution on dried droplets of BSA placed in the center of small pieces of aluminum foil. The dissection solution was aspirated and replaced by 1 $\mathrm{ml}$ of cold incubation medium (see composition below) containing vanadate to block the pump in a configuration that allows ouabain binding. Incubation lasted for $30 \mathrm{~min}$ at $37^{\circ} \mathrm{C}$, which allows maximal binding in CCD of both normal and NS rats. Then the tubules were rinsed four times with ice-cold dissection solution and kept at $0-4^{\circ} \mathrm{C}$ for $60 \mathrm{~min}$. After two additional rinsings, the pieces of aluminum foil were dropped into counting vials containing $0.5 \mathrm{ml}$ of $1 \%(\mathrm{wt} / \mathrm{vol}$ ) deoxycholic acid, and the radioactivity was counted by liquid scintillation.

Total and nonspecific $\left[{ }^{3} \mathrm{H}\right]$ ouabain binding were measured on seven replicates. In addition 5-10 blanks (incubated without tubule) were used for background determination.

Total $\left[{ }^{3} \mathrm{H}\right.$ ]ouabain binding was determined using an incubation medium containing (mM): 250 sucrose, $3 \mathrm{MgSO}_{4}, 3 \mathrm{Na}_{2} \mathrm{HPO}_{4}, 1$ $\mathrm{NaVO}_{3}, 10$ Tris $\mathrm{HCl}$, and more than $\left[0.2{ }^{3} \mathrm{H}\right]$ ouabain (Dupont de Nemours, New England Nuclear, Boston, MA, 10-20 Ci $\cdot \mathrm{mmol}^{-1}$ ). Nonspecific binding was measured in the same incubation medium added with $30 \mathrm{mM} \mathrm{KCl}$ and $5 \mathrm{mM}$ unlabeled ouabain. Specific $\left[{ }^{3} \mathrm{H}\right]-$ ouabain binding was calculated as the difference between the mean values of total and nonspecific binding and was expressed as $\mathrm{fmol} \cdot \mathrm{mm}^{-1}$. Data are means $\pm \mathrm{SE}$ from several animals.

Statistics and calculations. Curves of inhibition of Na-K-ATPase activity by ouabain were fitted using iterative, nonlinear least square analysis, which allowed the estimation of apparent $K i$ and specific activity (nonlinear 1.0). Statistical comparisons between groups were performed by Student's $t$ test for unpaired data.

\section{Results}

Experimental model. The efficiency of the procedure to induce the nephrotic syndrome was ascertained by the presence of ascites and proteinuria (positive Albustix ${ }^{\circledR}$, Ames, UK).

$N a-K$-ATPase hydrolytic activity, ouabain sensitive ${ }^{86} R b$ influx and efficiency of the pump. Na-K-ATPase hydrolytic activity and ouabain sensitive ${ }^{86} \mathrm{Rb}$ influx were measured in CCD isolated from the same rats, and results are mean values $\pm \mathrm{SE}$ from six different animals. In CCD of nephrotic rats, there was a twofold increase of the Na-K-ATPase specific activity (NS vs. control rats: $34.05 \pm 2.10$ vs. $17.98 \pm 0.73 \mathrm{pmol} \mathrm{ATP} \cdot \mathrm{min}^{-1}$. $\mathrm{mm}^{-1}, P<0.001$ ) (Fig. $1 A$ ), as well as of ouabain sensitive ${ }^{86} \mathrm{Rb}$ uptake (Fig. $1 B$ ), (NS vs. control rats: $14.4 \pm 0.7$ vs. $7.4 \pm 0.4$ peq $\left.\mathrm{Rb} \cdot \mathrm{min}^{-1} \cdot \mathrm{mm}^{-1}, P<0.001\right)$. The efficiency of
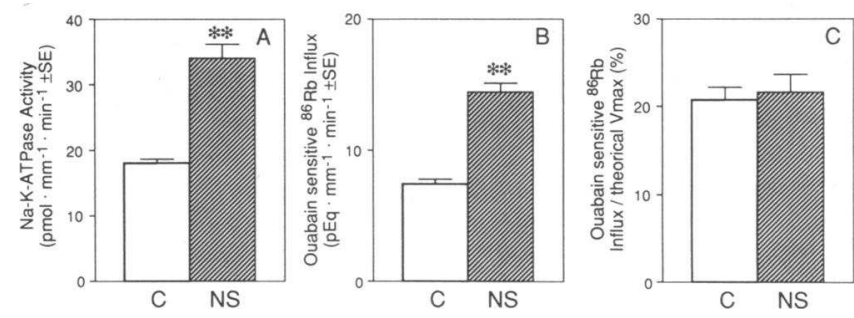

Figure 1. Na-K-ATPase hydrolytic activity $(A)$, ouabain-sensitive $\mathrm{Rb}$ uptake $(B)$, and efficiency of the Na-K-ATPase $(C)$ in CCD from control (C, open bars) and nephrotic rats (NS, hatched bars).

$\mathrm{Na}$-K-ATPase hydrolytic activity was determined under optimal conditions, ouabain-sensitive $\mathrm{Rb}$ uptake was measured under initial rate conditions, and Na-K-ATPase efficiency was calculated as the ratio of the initial rate of ouabain-sensitive $\mathrm{Rb}$ uptake over the maximal $\mathrm{Na}$ K-ATPase pumping rate (calculated from the measured hydrolytic activity, assuming a stoichiometry of 2Rb/ATP). Na-K-ATPase and ouabain-sensitive $\mathrm{Rb}$ uptake were measured in $\mathrm{CCD}$ from the same animals. Results are expressed as means \pm SE from six independent experiments. Values statistically different from controls were determined by Student's $t$ test for unpaired data: ${ }^{* *} P<0.001$. 
$\mathrm{Na}-\mathrm{K}-\mathrm{ATPase}$ was calculated as the $\mathrm{Vi} / \mathrm{Vmax}$ ratio where $\mathrm{Vi}$ is the Na-K-ATPase pumping activity measured in intact cells (ouabain sensitive ${ }^{86} \mathrm{Rb}$ uptake) in the presence of physiological rate limiting intracellular sodium (14), and Vmax is the theoretical maximal Na-K-ATPase pumping activity calculated from the specific hydrolytic activity assuming a stoichiometry of $1 \mathrm{ATP} / 2 \mathrm{Rb}$. Fig. $1 C$ shows that the efficiency of the $\mathrm{Na}-\mathrm{K}-\mathrm{ATPase}$ in percent was identical in NS and in control rats $(21.7 \pm 1.9$ vs. $20.7 \pm 1.5) \cdot \mathrm{Mg}$-dependent ATPase activity (NS vs. control rats: $13.1 \pm 3.6$ vs. $13.1 \pm 2.8$ pmol . ATP $\cdot \mathrm{mm}^{-1} \cdot \mathrm{min}^{-1}$ ) and ouabain insensitive ${ }^{86} \mathrm{Rb}$ uptake (NS vs. control rats: $2.1 \pm 0.2$ vs. $2.0 \pm 0.3 \mathrm{peq} \mathrm{Rb} \cdot \mathrm{mm}^{-1} \cdot \mathrm{min}^{-1}$ ) did not differ between NS and control rats.

Specific $\left[{ }^{3} \mathrm{H}\right]$ ouabain binding and $\mathrm{Na}-\mathrm{K}$-ATPase turnover rate. Specific $\left[{ }^{3} \mathrm{H}\right]$ ouabain binding was measured in $\mathrm{CCD}$ from the same six animals used in the previous experiments, and results are given as mean values \pm SE. In NS rats, specific $\left[{ }^{3} \mathrm{H}\right]$ ouabain binding, i.e., the number of Na-K-ATPase units per $\mathrm{mm}$ of CCD length, was decreased by $20 \%$ as compared with controls (NS vs. control rats $6.9 \pm 0.7$ vs. $9.0 \pm 0.6$ $\mathrm{fmol} \cdot \mathrm{mm}^{-1}, P<0.05$ ) (see Fig. $2 A$ ).

Therefore, the turnover rate of Na-K-ATPase, which was calculated as the ratio of the specific hydrolytic activity of $\mathrm{Na}$ K-ATPase over the specific ouabain binding (determined in the same animal assuming one binding site per Na-K-ATPase unit), was increased by more than twofold in NS rats (Fig. $2 B$ ) (NS vs. control rats: $5,053 \pm 361$ vs. $2,043 \pm 124$ cycles $\cdot \mathrm{min}^{-1}$, $P<0.001$ ).

Ouabain sensitivity of $\mathrm{Na}-\mathrm{K}-\mathrm{ATP}$ ase. The concentration of $\left[{ }^{3} \mathrm{H}\right]$ ouabain used in the previous set of experiments is just sufficient to saturate the specific binding sites in CCD of normal rats (16). Thus, the paradoxical apparent decrease in specific $\left[{ }^{3} \mathrm{H}\right]$ ouabain binding observed during NS could be due either to a reduced affinity of Na-K-ATPase for ouabain or to an actual decrease in the number of binding sites. To solve this alternative, we evaluated the affinity of Na-K-ATPase for ouabain in the CCD from both NS and control rats. For this purpose, we determined the sensitivity of Na-K-ATPase hydrolytic activity toward increasing concentrations of ouabain. Indeed, direct measurement of the affinity of ouabain is not feasible in binding experiments because increasing $\left[{ }^{3} \mathrm{H}\right]$ ouabain concentration also increases nonspecific binding beyond acceptable limits. In these experiments, ouabain was added at six times the
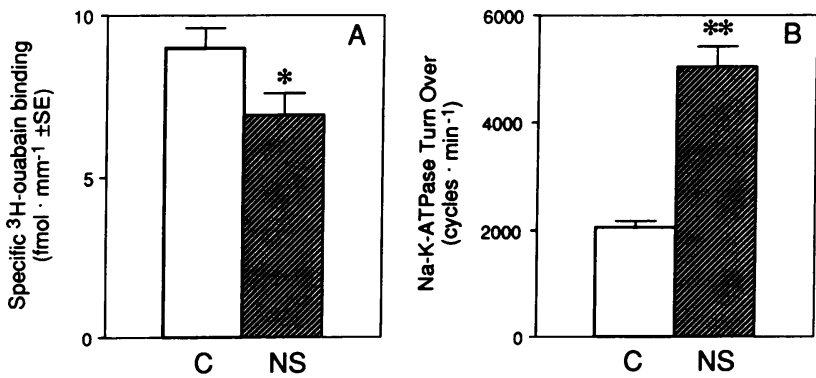

Figure 2. Specific $\left[{ }^{3} \mathrm{H}\right.$ ]ouabain binding $(A)$, and Na-K-ATPase turnover rate $(B)$ in CCD from control $(C$, open bars) and nephrotic rats (NS, hatched bars). Na-K-ATPase turnover rate was calculated as the ratio of the Na-K-ATPase hydrolytic activity (Fig. $1 A$ ) over the specific $\left[{ }^{3} \mathrm{H}\right]$ ouabain binding measured in $\mathrm{CCD}$ from the same animals (Fig. $2 \mathrm{~A}$ ). Results are expressed as means \pm SE from six independent experiments. Values statistically different from controls were determined by Student's $t$ test for unpaired data: ${ }^{*} P<0.05 ;{ }^{* *} P$ $<0.001$. required final concentrations $\left(10^{-8}\right.$ to $\left.10^{-3} \mathrm{M}\right)$ in the $0.2 \mathrm{ml}$ of water used for the freezing/thawing step. Inhibition of $\mathrm{Na}-\mathrm{K}-$ ATPase activity by increasing ouabain concentrations in CCD of control and NS rats is shown in Fig. $3 A$ and Fig. $3 B$, respectively. These curves exhibited a bimodal inhibition pattern indicating that, in CCD of both control and NS rats, two populations of Na-K-ATPase could be identified by their ouabain sensitivity: a component highly sensitive to ouabain (apparent $K i$ : Control, $1.4 \times 10^{-6} \mathrm{M}$; NS, $0.9 \times .10^{-6} \mathrm{M}$ ) and a component with a lower sensitivity (apparent $K \mathrm{i}$ : Control, $2.6 \times 10^{-4}$ $\mathrm{M}$; NS, $1.1 \times 10^{-4} \mathrm{M}$ ).

At that point, it should be noted that the concentration of ouabain used in binding assay $\left(2.10^{-4} \mathrm{M}\right)$ is sufficient to saturate binding sites (16) although it only inhibits Na-K-ATPase activity by $70 \%$ (Fig. 3). This apparent discrepancy is explained by the presence of $\mathrm{K}^{+}$ions, a competitor of ouabain, in the ATPase hydrolytic activity assay and by its absence in ouabain binding assay.

Proportion of Na-K-ATPase activity with high and low sensitivity to ouabain. In CCD of both control and NS rats, the component with high ouabain sensitivity was completely inhibited with $5 \cdot 10^{-6} \mathrm{M}$ ouabain, a concentration that inhibits only a small fraction $(<10 \%)$ of the component with low ouabain
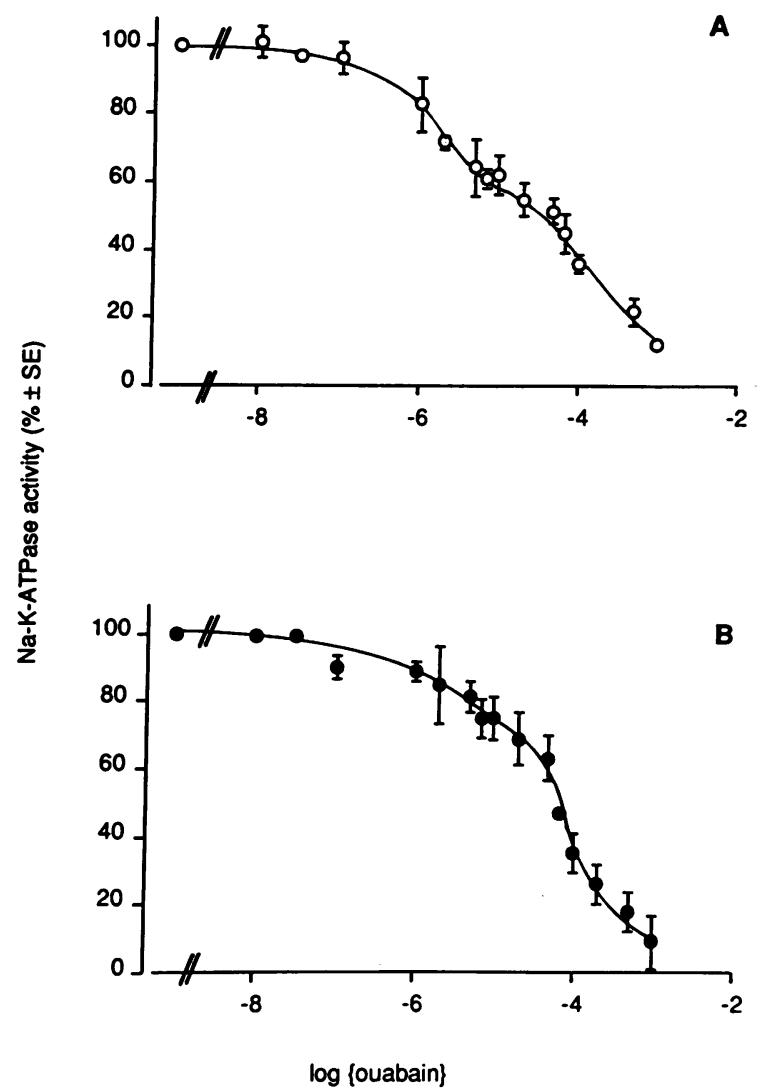

Figure 3. Ouabain sensitivity of Na-K-ATPase in CCD from control $(A)$ and nephrotic rats $(B)$. Na-K-ATPase hydrolytic activity was measured in the absence or in the presence of increasing concentrations $\left(10^{-8}\right.$ to $\left.10^{-3} \mathrm{M}\right)$ of ouabain. Results are means \pm SE from three to eight independent measurements in eight animals. The Na-K-ATPase populations with high ouabain sensitivity exhibited apparent $K \mathrm{i}$ of $1.4 \times 10^{-6} \mathrm{M}$ and $0.9 \times 10^{-6} \mathrm{M}$; whereas the Na-K-ATPase populations with lower ouabain sensitivity exhibited apparent $K 1$ of $2.6 \times 10^{-4} \mathrm{M}$ and $1.1 \times 10^{-4} \mathrm{M}$ in control and nephrotic rats, respectively. 
sensitivity. Therefore, the contribution of the high-affinity component was evaluated by the difference between total ATPase activity ( or the activity measured at any ouabain concentration between 0 and $5 \times 10^{-6} \mathrm{M}$ ) and the activity measured in the presence of $5.10^{-6} \mathrm{M}$ ouabain, whereas that of the low-affinity component was taken as the remaining activity, i.e., the difference between the activity measured in the presence of $5.10^{-6} \mathrm{M}$ ouabain (or any ouabain concentration comprised between 5 $\times 10^{-6} \mathrm{M}$ and $10^{-3} \mathrm{M}$ ) and $\mathrm{Mg}$-ATPase activity. Fig. 4 depicts the ouabain sensitivity of total Na-K-ATPase activity $(A)$, of the high affinity component $(B)$ and the low affinity component $(C)$. Clearly, it shows that $(a)$ as previously observed, the total Na-K-ATPase activity was enhanced in NS compared with controls $(A)$ (NS vs. control rats: $26.0 \pm 1.0$ vs. $17.6 \pm 1.2$ $\mathrm{pmol}$ ATP $\left.\cdot \mathrm{mm}^{-1} \cdot \min ^{-1}, P<0.001\right)$; $(b)$ the absolute contribution of the high affinity fraction was similar in control and NS $(B)$ (NS vs. controls: $5.9 \pm 1.2$ vs. $5.7 \pm 1.1$ pmol ATP $\left.\cdot \mathrm{mm}^{-1} \cdot \mathrm{min}^{-1}\right)$; so that, $(c)$ the enhancement of $\mathrm{Na}-\mathrm{K}$ ATPase activity in NS was entirely accounted for by the enhancement of the low-affinity component $(C)$ (NS vs. controls: $20.0 \pm 1.7$ vs. $11.9 \pm 1.5 \mathrm{pmol} \mathrm{ATP} \cdot \mathrm{mm}^{-1} \cdot \mathrm{min}^{-1}, P$ $<0.001)$; (d) finally, it confirmed that the apparent $K \mathbf{i}$ of the two components were not significantly altered in NS rats.

\section{Discussion}

The present study confirms the increase in the specific hydrolytic activity of Na-K-ATPase in CCD of nephrotic rats previously reported from our laboratory (1). In addition, it demonstrates that the ouabain-sensitive ${ }^{86} \mathrm{Rb}$ uptake increased in parallel with $\mathrm{Na}-\mathrm{K}-\mathrm{ATPase}$ hydrolytic activity, providing further evidence for an increased ability to reabsorb sodium in CCD of rats with NS. These results agree with previous micropuncture experiments ( 2 ) that indicated that the CCD was the site of the increased sodium reabsorption occurring in NS.

Measurement of Na-K-ATPase hydrolytic activity on permeabilized cells under optimal conditions obviates regulatory factors that do not alter the Vmax of the enzyme, whereas determination of ouabain sensitive moiety of ${ }^{86} \mathrm{Rb}$ uptake is a measure of the cation-transporting activity of the Na-K-ATPase in intact cells under conditions where intracellular sodium is rate limiting $(6-8,14)$ and transmembrane ion gradients are comparable to those prevailing in vivo. The efficiency of activation of the Na-K-ATPase in intact cells was $20 \%$ in both control and NS rats, which is in the range reported previously in CCD of normal rats (14). This percentage of $\mathrm{Na}-\mathrm{K}-\mathrm{ATPase}$ activation is mainly determined by intracellular sodium concentration (5-7), by the sodium affinity of the enzyme $(5,8)$ and, to a lesser extent, by $K$ conductance ( 9$)$ and transmembrane voltage (10). The identical efficiencies of the Na-K-ATPase found in normal and NS rats argue against the participation of these regulatory factors in the increase in ouabain-sensitive ${ }^{86} \mathrm{Rb}$ uptake observed in NS rats.

Contrasting with enhanced Na-K-ATPase activity, the specific $\left[{ }^{3} \mathrm{H}\right]$ ouabain binding was decreased in CCD of nephrotic rats, compared with controls. Data presented in Fig. 3 showed that ouabain sensitivities for concentrations of between $10^{-8} \mathrm{M}$ and $10^{-3} \mathrm{M}$ were similar and allowed the identification of two populations of Na-K-ATPase in CCD from control and NS rats. The first population displayed a high sensitivity to ouabain (apparent $K \mathrm{i}$ : $0.9-1.4 \times 10^{-6} \mathrm{M}$ ) whereas the second was
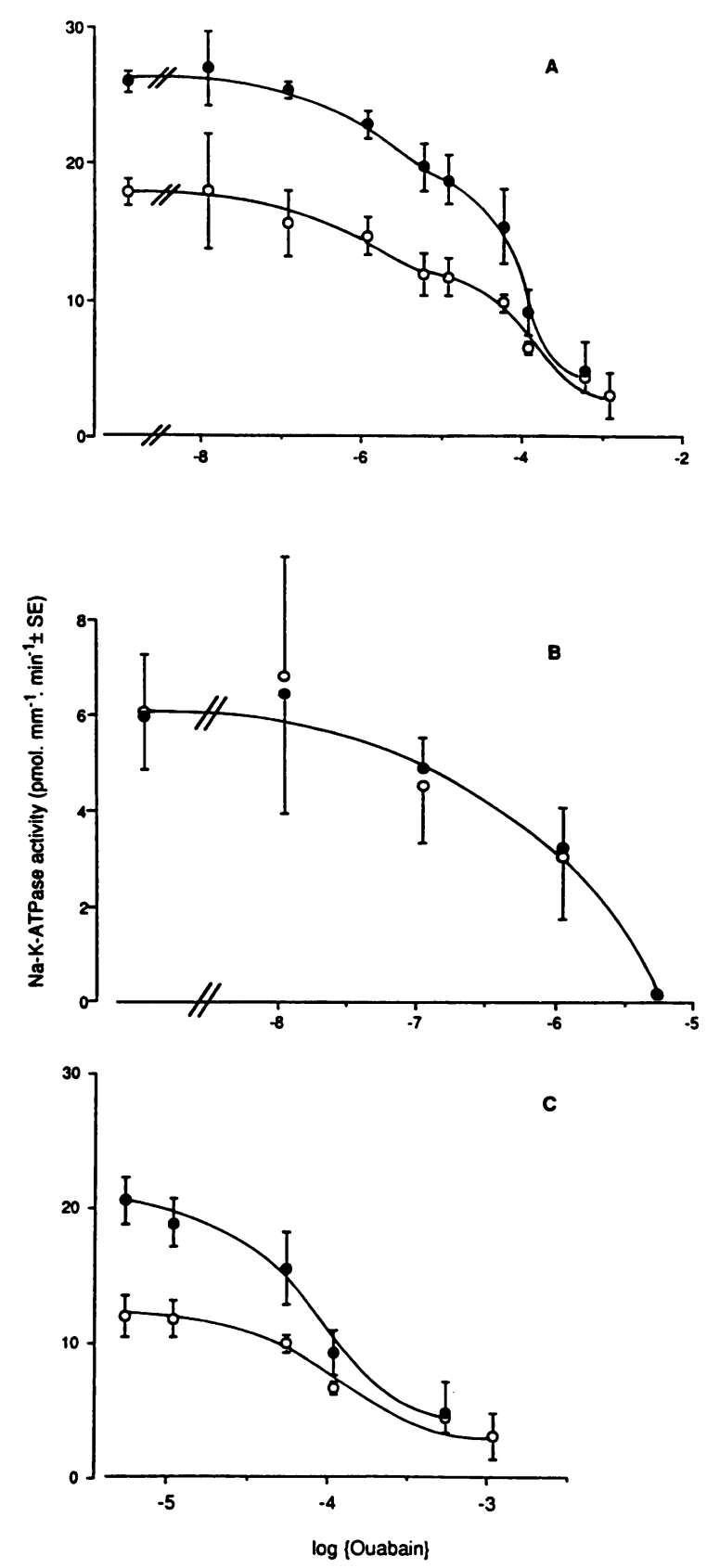

Figure 4. Ouabain sensitivity of the total Na-K-ATPase activity $(A)$, of the component with high affinity $(B)$ and of the component with low affinity $(C)$ in the CCD of normal rats $(o)$ and of with NS $(o)$. The activity of the high affinity component was calculated as the difference between the activity measured at a given concentration of ouabain (from 0 to $5 \times 10^{-6} \mathrm{M}$ ) minus that measured with $5 \times 10^{-6}$ $M$ ouabain. The activity of the low-affinity component was calculated as the difference between the activity measured at a given concentration of ouabain (from $5 \times 10^{-6} \mathrm{M}$ to $10^{-3} \mathrm{M}$ ) minus the basal $\mathrm{Mg}-\mathrm{ATPase}$ activity. Data are means $\pm \mathrm{SE}$ from eight experiments.

less sensitive to this inhibitor (apparent $K 1$ about 1.1-2.6 $\left.\times 10^{-4} \mathrm{M}\right)$. Assuming that the affinity to the ouabain binding sites and the sensitivity of the Na-K-ATPase activity for ouabain of normal and nephrotic animals vary in parallel, the same proportion of binding sites was occupied by ouabain in both control and NS animals. Therefore, the number of Na-K- 
ATPase units was actually decreased in CCD of NS rats. However, binding experiments at low ouabain concentration are not sensitive enough to allow the determination of the relative contribution to this decrease of each of the two populations of $\mathrm{Na}-\mathrm{K}-\mathrm{ATPase}$ present in rat CCD.

Sweadner first provided evidence for the existence of several isoenzymes of the Na-K-ATPase $\alpha$ subunit in brain (17). By now, three isoforms of the $\alpha$ subunit have been identified in different tissues where they are expressed to various extents $(18-22)$. These isoforms differ functionally from each other by their sensitivity to ouabain, the $\alpha_{1}$ isoform being less sensitive than the $\alpha_{2}$ and $\alpha_{3}$ isoforms $(17,20,21)$. Our data are in agreement with previous observations in several rat tissues, since in adipocytes (20), skeletal muscle (23) and brain (24), the $\alpha_{2}$ and $\alpha_{1}$ subunits have been identified and their respective sensitivities to ouabain are very close to the apparent $K i$ of the two populations of Na-K-ATPase that we found in rat CCD. These results suggest, although they do not demonstrate, the existence of two different isoforms of the Na-K-ATPase subunit in the rat $\mathrm{CCD}$ despite the fact that the presence in the kidney of isoforms other than $\alpha_{1}$ remains controversial $(18,25,26)$. Further studies are clearly needed but, due to the heterogeneity of the kidney, the interpretation of the results of such experiments will be difficult. Only experiments performed on homogenous, well-defined nephron segments will provide reliable results.

The fact that the ouabain sensitivity of the two populations of Na-K-ATPase was markedly different (apparent $K i$ differ by more than two orders of magnitude) permitted us to quantitate the relative contribution of each of them to the total activity of Na-K-ATPase. The activity of the population with the highest ouabain sensitivity was the same in CCD from both control and NS rats, whereas the activity of the population with lower ouabain sensitivity, which accounts for the largest part of total Na-K-ATPase activity, was increased more than twofold during NS. Therefore, in CCD of NS rats, the activity of the Na-KATPase subclass of low ouabain sensitivity was specifically enhanced. From these data, it appears that the two Na-K-ATPase subpopulations can be regulated separately.

The similarity of ouabain affinity in control and nephrotic rats (Fig. 3) validates the ouabain binding data (Fig. $2 A$ ), which in turn validates the calculation of the turnover rates of the Na-K-ATPase (Fig. $2 \mathrm{~B}$ ). These results indicate that an increase in the turnover of the enzyme is responsible for the enhancement of the Na-K-ATPase activity in CCD of nephrotic rats. The turnover rate was likely increased at the expense of the low ouabain affinity population. However, in the absence of a reliable methodology allowing the direct determination of the number of $\mathrm{Na}-\mathrm{K}-\mathrm{ATPase}$ units belonging to the forms of either high or low ouabain affinity, the turnover of each subclass could not be measured precisely. The enhanced turnover rate of $\mathrm{Na}-\mathrm{K}$-ATPase can result either from a stimulation or from a deinhibition involving a putative regulatory factor. Further investigations will be necessary to clarify this point.

The stimulation of sodium reabsorption capacity in the CCD of NS rats revealed by micropuncture studies (2) implies that both apical sodium entry and basolateral sodium exit through the pump are enhanced in parallel. This raises the possibility that stimulation of Na-K-ATPase might not be a primary defect during NS but rather might be secondary to the stimulation of apical sodium entry via an increase in intracellu- lar sodium concentration. However, this seems unlikely since (a) an increased intracellular $\mathrm{Na}$ concentration upregulates Na-K-ATPase activity by mobilizing new pump units, as revealed by increased ouabain-binding capacity $(27)$, and $(b)$ the finding of a similar pumping efficiency of Na-K-ATPase in normal and NS rats (Fig. $1 C$ ) suggests that intracellular $\mathrm{Na}^{+}$ concentration is not altered in the CCD of NS rats.

The present findings clearly shows the presence of two populations of Na-K-ATPase in the rat CCD. The increase in Na-KATPase hydrolytic activity is physiologically relevant in NS rats since it corresponds to an actual stimulation of the pumping rate of the enzyme in intact cells. In NS, the activation of the enzyme activity is due to the increase in the turnover rate of the Na-K-ATPase. The population with low sensitivity to ouabain accounted for the totality of the enhanced Na-K-ATPase activity, demonstrating an individual regulation for each $\mathrm{Na}$ K-ATPase population. Thus, on the basis of these experiments it is proposed that an abnormal regulation of a specific $\mathrm{Na}-\mathrm{K}$ ATPase subpopulation in the CCD participates to the defect responsible for the edema formation in this type of nephrotic syndrome.

\section{Acknowledgments}

We thank Pr. L. Girardier, Dr. P. Muzzin, and Dr. M. Rossier for helpful discussion and for assisting us in for fitting curves, and E. Gaillard for excellent secretarial skills.

\section{References}

1. Vogt, B., and H. Favre. 1991. Na-K-ATPase activity and hormones in single nephron segments from nephrotic rats. Clin. Sci. Lond. 80:599-604.

2. Bernad, D. B., E. A. Alexander, W. G. Couser, and N. G. Levinsky. 1978 Renal sodium retention during volume expansion in experimental nephrotic syndrome. Kidney Int. 14:478-485.

3. Hamlyn, J. M., M. P. Blaustein, S. Bova, D. W. Ducharme, D. W. Harris, F. Mandel, W. R. Mathews, and J. Ludens. 1991. Identification and characterization of a ouabain-like compound from human plasma. Proc. Natl. Acad. Sci. USA. 88:6259-6263.

4. Féraille, E., M. Rousselot, B. Vogt, and H. Favre. 1991. Differences in ouabain and endogenous ouabain displacing factor sensitivities of the Na-K-ATPase along the rat nephron. J. Am. Soc. Nephrol. 2:736. (Abstr.)

5. Barlet-Bas, C., L. Cheval, E. Féraille, S. Marsy, and A. Doucet. 1991. Regulation of tubular Na-K-ATPase. In Nephrology. M. Hatano, editor. Springer-Verlag, Tokyo. 419-434.

6. Jorgensen, P. L. 1986. Structure function and regulation of Na-K-ATPase in the kidney. Kidney Int. 29:10-20.

7. Skou, J. C. 1962. Preparation from mammalian kidney of the enzyme system involved in active of $\mathrm{Na}+$ and $\mathrm{K}+$. Biochim. Biophys. Acta. 58:314-325.

8. Lytton, J. 1985. Insulin affects the sodium affinity of the rat adipocyte (Na+, K+) ATPase. J. Biol. Chem. 260:10075-10080.

9. Karlish, S. J. D., R. Goldschleger, Y. Shahak, and A. Rephaeli. 1988 Charge transfer by the Na/K pump. Prog. Clin. Biol. Res. 268A:519-524.

10. Schulz, S. G. 1981. Homocellular regulatory mechanisms in sodium-transporting epithelia: avoidance of extinction by "flush-through". Am. J. Physiol. 241:F579-F590.

11. Frenk, S., I. Antonowitcz, J. M. Craig, and J. Metcoff. 1955. Experimental nephrotic syndrome induced in rats by aminonucleoside. Renal lesions and body electrolyte composition. Proc. Soc. Exp. Biol. Med. 89:424-427.

12. Imbert, M., D. Chabardès, M. Montégut, A. Clique, and F. Morel. 1975. Adenylate cyclase activity along the rabbit nephron as measured in single isolated segments. Pfluegers Arch. Eur. J. Physiol. 354:213-228.

13. Doucet, A., A. I. Katz, and F. Morel. 1979. Determination of Na-K-ATPase activity in single segments of the mammalian nephron. Am. J. Physiol. 237:F105-F113.

14. Cheval, L., and A. Doucet. 1990. Measurement of Na-K-ATPase mediated rubidium influx in single segments of rat nephron. Am. J. Physiol. 259:F111-F121. 
15. El Mernissi, G., and A. Doucet. 1984. Quantitation of ${ }^{3} \mathrm{H}$-ouabain binding and turnover of Na-K-ATPase along the rabbit nephron. Am. J. Physiol. 247:F158-F167.

16. Doucet, A., and C. Barlet-Bas. 1989. Involvement of $\mathrm{Na}^{+}-\mathrm{K}^{+}-\mathrm{ATPase}$ in antinatriuretic action of mineralocorticoids in mammalian kidney. Curr. Top. Membr. Transp. 34:185-205.

17. Sweadner, K. J. 1979. Two molecular forms of $\left(\mathrm{Na}^{+}+\mathrm{K}^{+}\right)$-stimulated ATPase in brain. J. Biol. Chem. 254:6060-6067.

18. Arystarkhova, E. A., O. E. Lakhtina, and N. N. Modyanov. 1989. Immunodetection of Na-K-ATPase alpha-3-isoform in renal and nerve tissues. FEBS (Fed. Eur. Biochem. Soc.) Lett. 250:545-548.

19. Horowitz, B., C. B. Hensley, M. Quintero, K. K. Azuma, D. Putnam, and A. A. McDonough. 1990. Differential regulation of Na-K-ATPase $a_{1}, a_{2}$, and $b$ subunit mRNA and protein levels by thyroid hormones. J. Biol. Chem. 265:14308-14314.

20. Lytton, J., J. C. Lin, and G. Guidotti. 1985. Identification of two molecular forms of $\left(\mathrm{Na}^{+}, \mathrm{K}^{+}\right)$-ATPase in rat adipocytes. $J$. Biol. Chem . 260:1177-1184

21. Sweadner, K. J. 1989. Isozymes of the $\mathrm{Na}^{+} / \mathrm{K}^{+}$-ATPase. Biochim Biophys. Acta. 988:185-220.
22. Urayama, O., H. Shutt, and K. J. Sweadner. 1989. Identification of three isozyme proteins of the catalytic subunit of the Na-K-ATPase in rat brain. J. Biol. Chem. 264:8271-8280.

23. Hsu, Y. M., and G. Guidotti. 1991. Effects of hypokalemia on the properties and expression of the $\left(\mathrm{Na}^{+}, \mathrm{K}^{+}\right)$-ATPase of rat skeletal muscle. J. Biol Chem. 266:427-433.

24. Berreli-Bertrand, I., J. M. Maixent, G. Christe, and L. Lelièvre. 1990. Two active $\mathrm{Na} / \mathrm{K}$-ATPase of high affinity for ouabain in adult rat brain membranes Biochim. Biophys. Acta. 1021:148-156.

25. Doucet, A., and C. Barlet. 1986. Evidence for differences in the sensitivity to ouabain of Na-K-ATPase along the nephron of rabbit kidney. J. Biol. Chem. 261:993-995.

26. Farman, N., I. Corthesy-Theulaz, J. P. Bonvalet, and B. C. Rossier. 1991. Localization of a-isoforms of $\mathrm{Na}^{+}-\mathrm{K}^{+}$-ATPase in rat kidney by in situ hybridization. Am. J. Physiol. 260:C468-C474.

27. Barlet-Bas, C., C. Khadouri, S. Marsy, and A. Doucet. 1990. Enhanced intracellular sodium concentration in kidney cells recruits a latent pool of $\mathrm{Na}-\mathrm{K}$ ATPase whose size is modulated by corticosteroids. J. Biol. Chem . 265:7799 7803. 